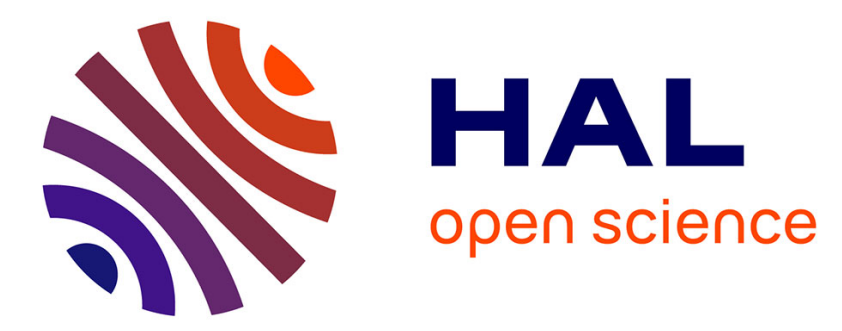

\title{
Controlled chlorination of polyamide reverse osmosis membranes at real scale for enhanced desalination performance
}

Rhea Verbeke, Samuel Eyley, Anthony Szymczyk, W. Thielemans, I.F.J. Vankelecom

\section{To cite this version:}

Rhea Verbeke, Samuel Eyley, Anthony Szymczyk, W. Thielemans, I.F.J. Vankelecom. Controlled chlorination of polyamide reverse osmosis membranes at real scale for enhanced desalination performance. Journal of Membrane Science, 2020, 611, pp.118400. 10.1016/j.memsci.2020.118400 . hal-02931993

\section{HAL Id: hal-02931993 https://hal.science/hal-02931993}

Submitted on 10 Sep 2020

HAL is a multi-disciplinary open access archive for the deposit and dissemination of scientific research documents, whether they are published or not. The documents may come from teaching and research institutions in France or abroad, or from public or private research centers.
L'archive ouverte pluridisciplinaire $\mathbf{H A L}$, est destinée au dépôt et à la diffusion de documents scientifiques de niveau recherche, publiés ou non, émanant des établissements d'enseignement et de recherche français ou étrangers, des laboratoires publics ou privés. 
Author Statement

Rhea Verbeke: design, coordination and performance of experiments, data analysis, manuscript writing and redaction. Samuel Eyley and Wim Thielemans: XPS experiments and data analysis. Anthony Szymczyk: zeta-potential experiments and data analysis. Ivo F.J. Vankelecom: supervision and manuscript reviewing. 


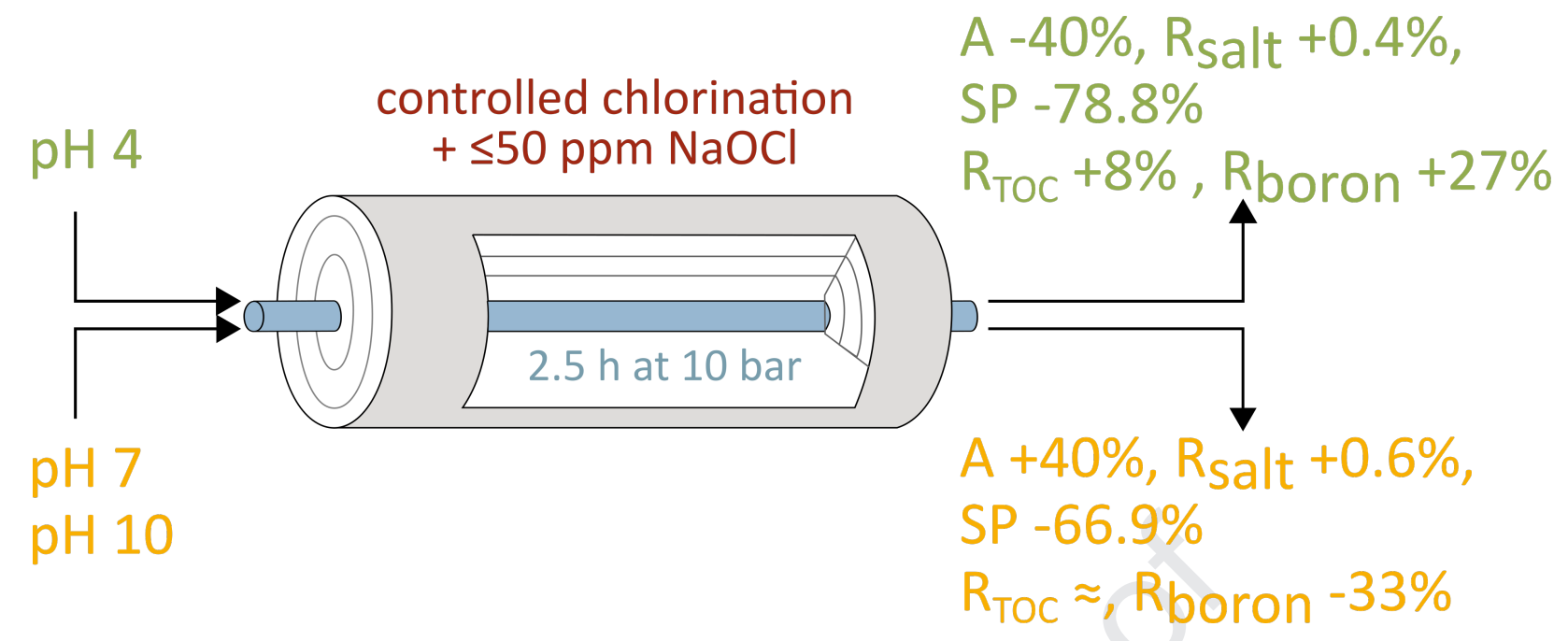


1 Controlled chlorination of polyamide reverse osmosis membranes at real scale 2 for enhanced desalination performance

3 Rhea Verbeke, ${ }^{a}$ Samuel Eyley, ${ }^{b}$ Anthony Szymczyk, ${ }^{c}$ Wim Thielemans, ${ }^{b}$ Ivo F.J. Vankelecom ${ }^{a^{*}}$

${ }^{a}$ Membrane Technology Group (MTG), Centre for Membrane Separations, Adsorption, Catalysis and Spectroscopy for Sustainable Solutions (cMACS), Faculty of Bioscience Engineering, KU Leuven, Celestijnenlaan 200F box 2454, 3001 Leuven, Belgium.

${ }^{\mathrm{b}}$ Chemical Engineering, KU Leuven Campus Kulak Kortrijk, Etienne Sabbelaan 53 box 7659, 8500 Kortrijk, Belgium

'Univ Rennes 1, CNRS, ISCR (Institut des Sciences Chimiques de Rennes) - UMR 6226, F-35000 Rennes, France

\section{Abstract}

State-of-the-art desalination and water purification processes use reverse osmosis and nanofiltration membranes. Their thin polyamide (PA) top-layers ensure concurrent high water permeances and salt rejections, but are also intrinsically sensitive to chlorine, originating from disinfectant added upstream. The chlorine resistance of PA-based membranes has been thoroughly studied at lab-scale, as opposed to industrial-scale membrane modules, where fundamental studies are lacking. Therefore, to better understand chlorine-induced changes in membrane performance and physicochemical properties at industrial scale, chlorination of commercial 8" elements was conducted at different pH (4-7-10) in pressurized modules with low chlorine concentrations $(0,1,20,50 \mathrm{ppm} \mathrm{NaOCl})$ during $2.5 \mathrm{~h}$. After 50 ppm acidic chlorination, water permeability decreased (-40\%) but salt rejection increased significantly $(+0.4 \%$, i.e., salt passage decreased with $-78.8 \%)$. Boron $(+27 \%)$ and isopropanol $(+8 \%)$ rejection also increased. Chlorination with $20 \mathrm{ppm} \mathrm{NaOCl}$ at pH 7 and with $50 \mathrm{ppm} \mathrm{NaOCl}$ at pH 10 caused boron rejection to drop with $-17 \%$ and $-33 \%$, respectively, but had negligible influence on isopropanol rejection. However, neutral and alkaline chlorination drastically improved water permeability with $+40 \%$ and salt rejection with $+0.6 \%$ (i.e., salt passage decreased with $-66.9 \%$ ), approaching and in some cases even slightly exceeding the salt/water permselectivity limit. It can thus be concluded that, under controlled conditions, chlorination can boost the performance of membrane modules. Significant changes in the membrane physicochemical properties were observed at pH 4 . At pH 7 and pH 10, a low chlorine-uptake in the PA network was observed, although no significant PA deterioration was observed with XPS and ATR-FTIR. This study is the first to fundamentally investigate chlorination of PA-based realscale membrane modules as a function of feed $\mathrm{pH}$. Furthermore, it provides a promising strategy to boost membrane performance at real scale and highlights the importance of chlorination conditions.

\section{Table Of Contents}




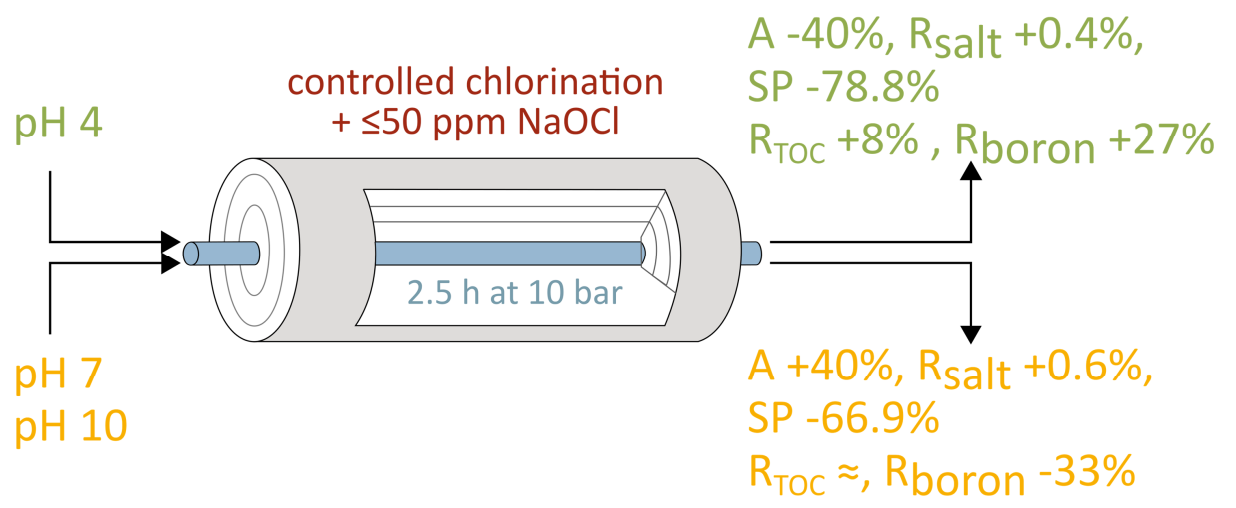

36

\section{Introduction}

Water treatment and desalination allow access to unconventional water sources and the (re-)use of contaminated waters for domestic and industrial consumption [1]. Water purification is hence an energy-efficient solution to overcome water scarcity, one of the major sustainable development goals of the United Nations [2]. State-of-the-art nanofiltration (NF) and reverse osmosis (RO) membranes have a polyamide (PA) top-layer, synthesized through the interfacial reaction of $m$-phenylene diamine (MPD) and trimesoyl chloride (TMC), that ensures excellent salt rejection and water permeance [3]. However, some micro-pollutants, such as endocrine disruptive compounds (EDCs), perfluoroalkyl substances (PFAs) and pharmaceutically active compounds (PhACs) are only poorly rejected and may cause health threats [4-7]. Another poorly rejected species is boron, typically found as boric acid at $4.5 \mathrm{mg} \mathrm{L}^{-1}$ in sea water [8]. As boron can also have adverse effects on human, animal and plant health, the World Health Organization (WHO) recommends a boron concentration of $2.4 \mathrm{mg} / \mathrm{L}$ for drinking water [9]. For agricultural irrigation, boron concentration should ideally be lower than $0.3 \mathrm{mg} \mathrm{L}^{-1}$ [10]. However, as current commercially available RO membranes exhibit boron rejections below $90 \%$, a single-pass RO process does not meet the regulatory guidelines for water sources with high boron content [11]. The low boron rejection of PA-based RO membranes is mainly caused by the small and uncharged nature of boric acid (pKa 8.6-9.2) under operating conditions $(<\mathrm{pH} 8$ ), impairing rejection mechanisms based on ion exclusion [12]. Additionally, hydrogen bonding between water and boric acid can possibly drag boric acid through the membrane [13]. To achieve low enough boron concentrations in permeates, membranes with improved rejection of small and uncharged species, as well as innovative desalination process designs are actively investigated $[7,12,14-17]$.

Another drawback of PA-based membranes is their sensitivity to chlorine, originating from disinfectant added upstream of the membrane filtration unit to minimize bio-fouling [18]. To avoid PA chlorination, chlorine removal is executed by dosing sodium metabisulfite or sodium bisulfite to the feed water in the so-called dechlorination step. However, complete continuous chlorine removal sometimes fails because of various practical factors, such as imperfect mixing of the chlorine-quencher, dechlorination system upsets and indirect monitoring of chlorine residuals. When this happens, accidental chlorination of the PA membrane takes place [18-21]. Chlorine, often dosed as sodium hypochlorite ( $\mathrm{NaOCl}$ ), will attack the PA network in various ways, depending on, amongst others, the $\mathrm{pH}$ of the feed solution and the presence of other ions [18]. Under acidic conditions, chlorine reacts through $\mathrm{N}$-chlorination of the amide bond, and direct or indirect ring-chlorination of the aromatic MPD moieties inside the PA network. In alkaline environments, chlorination-promoted hydrolysis takes place, causing cleavage of the amide 
bond [18]. Chlorine attack of the PA network generally leads to membrane performance losses, premature module replacement and disposal, plant productivity losses and increased costs $[18,22]$. However, under very specific chlorination conditions, higher salt rejections and water permeances have been observed [23-29].

The chlorine-induced effects on PA-based membrane physicochemical properties and performance have been long investigated at lab-scale. Due to the many different parameters affecting PA chlorination, contradictory results have been observed [18]. Additionally, the chlorination protocol most often consists of immersing small membrane coupons in the oxidizing $\mathrm{NaOCl}$ solution and their subsequent testing for filtration performance and characterization $[18,30]$. This approach is radically different from accidental chlorination in a water treatment plant, where the membrane module is pressurized and thus permeates water and rejects other compounds, while chlorination occurs. The information gathered at lab-scale on the chlorine-induced changes of physicochemical properties and performance is thus not only complex and sometimes contradicting, it is also very poorly transferrable to accidental chlorination at real-scale [18]. There is thus a need to fundamentally investigate the chlorine-induced effects on the performance and physicochemical properties of industrial-scale PA membrane modules while actively permeating under pressure.

In a previous study by the authors, controlled chlorination of BW30 membrane modules under acidic conditions $(\mathrm{pH} 4)$ was executed for the first time at industrial scale to systematically investigate its influence on membrane performance.[31] The aim of the present study is to understand the influence of the feed $\mathrm{pH}$ during chlorination on the performance and physicochemical characteristics of commercial PA modules. To achieve this, the $\mathrm{pH}$ of the feed solution was set at 7 or 10 , while dosing $0,1,20$ or 50 $\mathrm{ppm} \mathrm{NaOCl}$ for $2.5 \mathrm{~h}$. The changes in membrane performance (water permeability, and salt, boron and isopropanol passage) are demonstrated and the membrane physicochemical properties are systematically analyzed. A comparison with the earlier results obtained at $\mathrm{pH} 4$ is executed in order to obtain a complete picture of the concurrent influence of $\mathrm{pH}$ and chlorine concentration on PA-based membrane modules. This study further demonstrates the need for industrial-scale investigations, as the results of lab-scale testing are not representative and can often not be directly extrapolated to module format.

\section{Materials \& Methods}

\subsection{Membrane modules and chemicals}

FILMTEC $^{\text {TM }}$ BW30-400 and BW30-440i 8" spiral wound elements were used for this study. BW30 chemistry consists of an aromatic PA thin film with a thin coating, assumed to contain polyvinyl alcohol (PVA).[32,33] A schematic overview of the pilot-plant used for the experiments is shown in Figure $\mathbf{S 1 .}$

Sodium chloride ( $\mathrm{NaCl}, \mathrm{VWR}$ ), boric acid $\left(\mathrm{H}_{3} \mathrm{BO}_{3}, 4 \%, \mathrm{VWR}\right)$ and isopropanol (IPA, GC grade, MERCK) were used as solutes. Sodium hypochlorite ( $\mathrm{NaOCl}, 15 \%, \mathrm{MERCK})$ was used as chlorinating agent and the $\mathrm{pH}$ of the feed solution was adjusted to the desired $\mathrm{pH}$ with hydrochloric acid ( $\mathrm{HCl}, 1 \mathrm{M}, \mathrm{MERCK})$ or sodium hydroxide ( $\mathrm{NaOH}, 1 \mathrm{M}, \mathrm{MERCK})$. All chemicals were used as received.

\subsection{Chlorination protocol and membrane performance}

The chlorination protocol (Figure 1a) is identical to that used by the authors elsewhere [31], only the pH of the feed solution is here adjusted to 7 or 10, rather than to 4. For every condition (i.e., $\mathrm{pH}$ and $\mathrm{NaOCl}$ 
concentration), one membrane module was used. At the start of each chlorination experiment, the membrane elements are flushed with RO permeate with minimal permeation to ensure removal of preservation agents. Subsequently, a pre-chlorination standard test (pre-Cl-ST) is executed to determine the initial membrane performance under typical conditions (i.e. $2000 \mathrm{ppm} \mathrm{NaCl}, 100$ ppm isopropanol (IPA) and $5 \mathrm{ppm}$ boric acid at $15.5 \mathrm{bar}, 25^{\circ} \mathrm{C}$ and pH 8 , at a constant recovery of $15 \%$ ) under steady-state conditions, in recirculation mode. After flushing with RO permeate for $10 \mathrm{~min}$ in once-through mode, the chlorination step is executed in recirculation mode at 10 bar and $25^{\circ} \mathrm{C}$. The feed solution consists of RO permeate with solute concentrations of $500 \mathrm{ppm} \mathrm{NaCl}, 50 \mathrm{ppm}$ IPA and $5 \mathrm{ppm}$ boric acid, and spiked with $\mathrm{NaOCl}$ to achieve the desired concentration (0-1-20-50 ppm). $\mathrm{pH}$ adjustment (pH 4-7-10) is done through dosing $\mathrm{HCl}$ and $\mathrm{NaOH}$ and was adjusted during the chlorination step. After $2.5 \mathrm{~h}$ contact with chlorine, the solution is discarded and the membrane element flushed with RO permeate for $10 \mathrm{~min}$ in once-through mode. Then, a post-chlorination standard test (post-Cl-ST) is executed under the exact same conditions of the pre-Cl-ST to determine the altered membrane performance. Steady-state conditions were attained after $\sim 15 \mathrm{~min}$ and did not change up to at least $2 \mathrm{~h}$. Due to restrictions at the industrial plant, acquisition of long term post-chlorination performance data was not possible.

To investigate the influence of the chlorination step, the steady-state observed rejection (R) (or salt passage, SP) and water permeability (A) of both standard tests (pre-Cl-ST and post-Cl-ST) are compared, according to equations (1) and (2). To evaluate chlorine-induced changes in membrane permselectivity, the membrane salt permeance (B) is calculated, based on [34,35]. The reported standard deviations of $\Delta \mathrm{A}$ and $\Delta \mathrm{R}$ (or $\Delta \mathrm{SP}$ ) are based on the deviation of the average value of the measured water permeate flow and conductivity, respectively, of the pre- and post-Cl-ST after reaching steady-state.

$\Delta \mathrm{R}=\frac{\mathrm{R}_{\text {post }}-\mathrm{R}_{\text {pre }}}{\mathrm{R}_{\text {pre }}}($ Eq.1)

$\Delta \mathrm{A}=\frac{\mathrm{A}_{\text {post }}-\mathrm{A}_{\text {pre }}}{\mathrm{A}_{\text {pre }}}($ Eq. 2)

Observed TOC rejections, referring to IPA content in feed and permeate, are based on total organic carbon (TOC) measurements (TOC-L, Shimadzu). The IPA concentrations of the $\mathrm{pH} 7$ reference $(0 \mathrm{ppm}$ $\mathrm{NaOCl})$ post-Cl-ST and $\mathrm{pH} 10(50 \mathrm{ppm})$ pre-Cl-ST were inaccurate due to accidental IPA evaporation after sampling and are hence not reported. Observed boron rejection is measured with inductively coupled plasma optical emission spectrometry (Optima 8300, Perkin Elmer). The reported observed salt rejections are here based on conductivity measurements to better mimic industrial practices. The normalization procedure of the raw performance data to the designed performance of a BW30 8" element under the applied conditions was identical to that previously reported.[31] All reported salt, boron and IPA rejections are observed rejections.

During the chlorination step, the $\mathrm{pH}$ of the feed solution was measured with a portable HQ40D meter (Hach) and the chlorine content with a portable chlorine meter (AL400, Aqualytic and DR500, Hach, a bench lab spectrophotometer) at least 5 times during the $2.5 \mathrm{~h}$ and were adjusted if necessary. The concentrations used in this study should hence be seen as average values $(1 \pm 0.5,20 \pm 3.2$ and $50 \pm 1.7$ $\mathrm{ppm} \mathrm{NaOCl}$ ). Even with adjustments, the actual $\mathrm{pH}$ during the chlorination test varied roughly with 0.5 $\mathrm{pH}$-unit ( $\mathrm{pH} 4 \pm 0.5, \mathrm{pH} 7 \pm 0.5$ and $\mathrm{pH} 10 \pm 0.5$ ). The temperature during the chlorination step and the pre- and post-Cl-ST varied between $25 \pm 1{ }^{\circ} \mathrm{C}$, but this variation was accounted for during the normalization procedure. 
After the post-Cl-ST, the membrane module was opened and samples were extracted from the membrane sheets. They were rinsed with DI water and then allowed to dry under ambient conditions before characterization with attenuated total reflectance Fourier-transform infrared spectroscopy (ATRFTIR), X-ray photoelectron spectroscopy (XPS), scanning electron microscopy (SEM), atomic force microscopy (AFM) and zeta-potential measurements. The same operational procedure and data treatment methods were executed as mentioned previously [31] to allow results comparison, except for XPS quantification methodology. The reported standard deviations are based on triplicates, and on quadruplicates for XPS. In brief, following specifications apply:

158

159

160

ATR-FTIR. A Bruker Alfa ATR-FTIR with a diamond crystal was used to collect 32 scans for each measurement at a resolution of $4 \mathrm{~cm}^{-1}$. Each membrane was measured at three different positions to account for intra-sample variations.

AFM. AFM images were taken with a Dimension 3100D scanning probe microscope (from Bruker) operating in a soft tapping mode under ambient conditions (relative humidity 30\%). Commercial Sibased force probes-cantilevers (PPP-NCSTR, NanoAndMore $\mathrm{GmbH}$ ) with a nominal spring constant of 7 $\mathrm{N} / \mathrm{m}$ and with a typical tip radius of less than $7 \mathrm{~nm}$ were used. Obtained images were flattened with order 1 after scanning and the root-mean-squared roughness $\left(R_{R M S}\right)$ was calculated with WSXM [36].

SEM. SEM images were taken of sputter-coated samples $(5 \mathrm{~nm}$ of Pt) with a Phillips XL30 FEG instrument.

XPS. XPS was performed on a Kratos Axis Supra X-ray Photoelectron Spectrometer employing a monochromated Al $\mathrm{K}_{\alpha}(\mathrm{hv}=1486.7 \mathrm{eV}) \mathrm{X}$-ray source. The analyser was operated in fixed analyser transmission (FAT) mode with survey scans taken with a pass energy of $160 \mathrm{eV}$ and high resolution scans with a pass energy of $20 \mathrm{eV}$. All scans were acquired under charge neutralization conditions using a low energy electron gun within the field of the magnetic lens. The resulting spectra were processed using CasaXPS software. Binding energy was referenced to $C-C$ at $285.0 \mathrm{eV}$. High resolution spectra were fitted using the " $\operatorname{LF}(\alpha, \beta, w, m)$ " line shape corresponding to a numerical convolution of Lorentzian functions (with exponents $\alpha$ and $\beta$ for the high binding energy and low binding energy sides) with a Gaussian (width $\mathrm{m}$ ) and inclusion of tail-damping $(\mathrm{w})$ to provide finite integration limits. Details of this lineshape function are available in the CasaXPS documentation online.

Empirical relative sensitivity factors supplied by Kratos Analytical (Manchester, UK) were used for quantification. Use of these relative sensitivity factors does not account for any attenuation due to overlayers or other surface contamination and assumes a uniform depth distribution of elements within the information depth of the sample. Matrix effects are also discounted. Doublets due to non-zero orbital angular momentum were modelled using a fixed ratio of component peaks corresponding with the degeneracy of the total angular momentum states for that set of orbitals.

Zeta-potential. Membrane zeta-potential curves were determined with a SurPASS electrokinetic analyzer (Anton Paar) from streaming current measurements. For each measurement, two identical membrane coupons $(20 \mathrm{~mm} \times 20 \mathrm{~mm}$ ) were placed in the adjustable-gap cell (Anton Paar) and separated by a distance of $95 \pm 5 \mu \mathrm{m}$. Measurements were performed for $\mathrm{pH}$ ranging from $\sim 9$ to 2.5 using the automatic titration unit (SurPASS instrument) and applying pressure ramps from 0 to 300 
mbar. All measurements were performed at room temperature $\left(22 \pm 1{ }^{\circ} \mathrm{C}\right)$ under an inert atmosphere $\left(\mathrm{N}_{2}\right)$, according to [37].

\section{Results and discussion}

\subsection{Altered membrane performance after chlorination}

Clear changes in observed salt and boron rejection ( $\Delta R_{\text {conductivity }}$ and $\Delta R_{\text {boron, }}$ respectively) and water permeability $(\triangle \mathrm{A})$ as a function of $\mathrm{pH}$ and $\mathrm{NaOCl}$ concentration are observed before and after chlorination (Figure $\mathbf{1 b}, \mathbf{c}, \mathbf{d}$ ). The rejection of boron, present as boric acid $\left(\mathrm{H}_{3} \mathrm{BO}_{3}\right)$ during pre- and postCl-ST [38], and IPA (Figure S2) is investigated to assess the impact of chlorination on the passage of neutral solutes, as compared to charged ions from $\mathrm{NaCl}$. Positive (negative) $\Delta \mathrm{R}$ or $\Delta \mathrm{A}$ values indicate that chlorination increases (decreases) membrane solute rejection and water permeability during the post$\mathrm{Cl}-\mathrm{ST}$, as compared with the pre-Cl-ST. The changes in rejection and water permeance for the reference membranes (i.e., $0 \mathrm{ppm} \mathrm{NaOCl}$ at $\mathrm{pH}$ 4-7-10) denote intrinsic changes between the pre- and post-ST unrelated to chlorination.

a

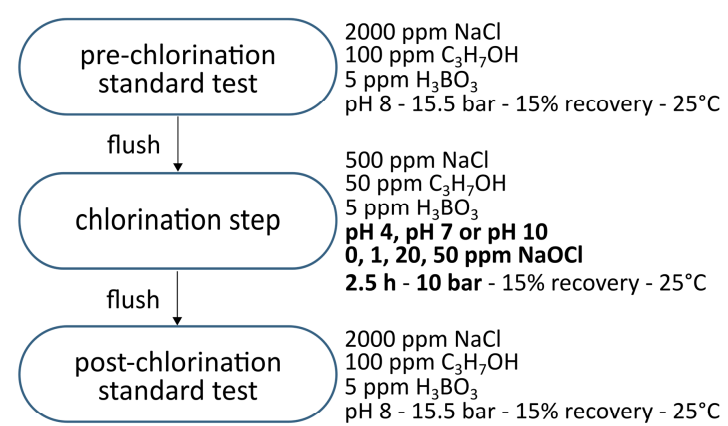

C

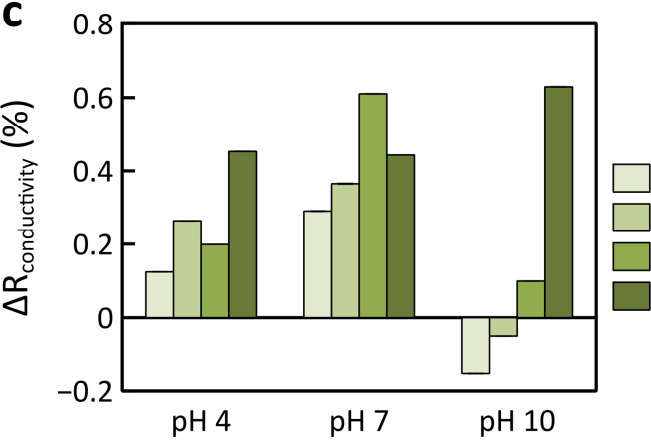

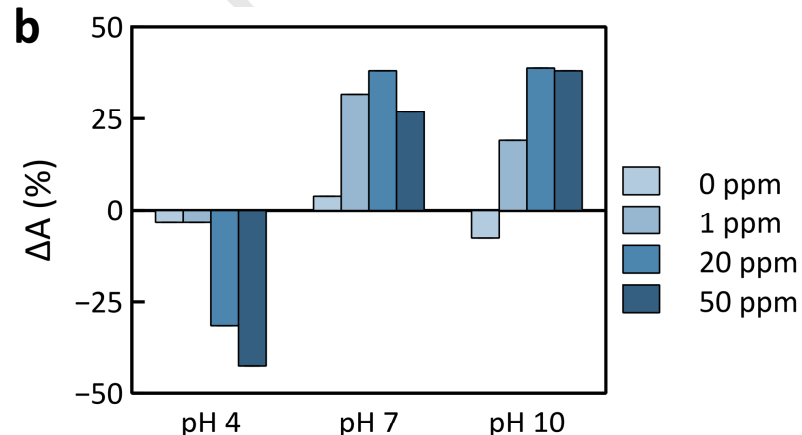

d

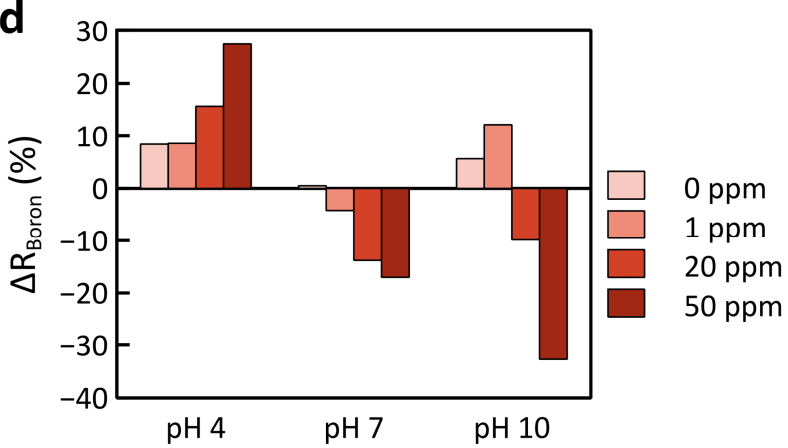

Figure 1. a) Scheme of the active chlorination protocol of BW30 membrane modules at real scale. All three steps (prechlorination standard test, chlorination step, post-chlorination standard test) were executed in recirculation mode with RO permeate as feed water. b) Difference in water permeability coefficient $(\Delta \mathrm{A})$ between pre- and post-Cl-ST as a function of $\mathrm{pH}$ and $\mathrm{NaOCl}$ concentration. c) Difference in observed salt rejection, based on conductivity measurements $\left(\Delta \mathrm{R}_{\text {conductivity }}\right)$, between pre- and post-Cl-ST as a function of $\mathrm{pH}$ and $\mathrm{NaOCl}$ concentration. d) Difference in observed boron rejection $\left(\Delta \mathrm{R}_{\text {boron }}\right)$ between pre- and post-Cl-ST as a function of $\mathrm{pH}$ and $\mathrm{NaOCl}$ concentration. Reported values and standard deviations are based on steadystate rejection and water permeate flow during pre- and post-Cl-ST. Standard deviations are mostly not visible due to low values. Experimental conditions of pre- and post-Cl-ST: RO permeate at 15.5 bar with $\mathrm{NaCl}$ (2000 ppm), isopropanol (100 ppm) and boric acid ( $5 \mathrm{ppm})$, at $\mathrm{pH} 8$, at $25^{\circ} \mathrm{C}$ and at a recovery of $15 \%$.

After acidic chlorination, the A-value decreases and salt rejection increases proportionally with increasing chlorine concentration. After contact with $50 \mathrm{ppm} \mathrm{NaOCl}$ for $2.5 \mathrm{~h}$, the A-value decreases 
down to $-40 \%$ of its initial value, while the salt rejection increases with $+0.4 \%$ and boron rejection with $+27 \%$. In absolute terms, this means that water permeability decreases from 2.78 to $1.61 \mathrm{Lm}^{-2} \mathrm{~h}^{-1} \mathrm{bar}^{-1}$, that salt rejection increased from $99.43 \%$ to $99.88 \%$, and boron rejection increases from $58.06 \%$ to $73.98 \%$ (Figure 2). The values of salt and boron passage during the pre-and post-Cl-ST and their differences can be found in Figures S3-4. The rejection of IPA also increases after acidic chlorination with $20 \mathrm{ppm}$ and $50 \mathrm{ppm} \mathrm{NaOCl}$ (Figure S2). This means that the observed rejection of both neutral (i.e., boron at $\mathrm{pH} \mathrm{8,} \mathrm{and} \mathrm{IPA)} \mathrm{and} \mathrm{charged} \mathrm{solutes} \mathrm{increases} \mathrm{after} \mathrm{acidic} \mathrm{chlorination.} \mathrm{However,} \mathrm{the}$ chlorinated membranes at $\mathrm{pH} 4$ follow the typical selectivity-permeability trade-off [39], meaning that a chlorine-induced water permeance decrease is accompanied by a rejection increase, as clearly demonstrated in Figure 3a. The chlorinated membranes do thus not exceed the upper bound limit. Nevertheless, acidic $(\mathrm{pH} 4)$, low dose $(\leq 50 \mathrm{ppm})$ and short time $(2.5 \mathrm{~h})$ chlorination appears as a promising modification strategy to achieve short-term high purity waters with high boron removal, which is often required for health concerns [40], albeit with lower water productivity. 


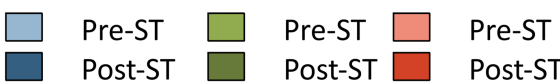

Post-ST $\square$ Post-ST $\square$ Post-ST

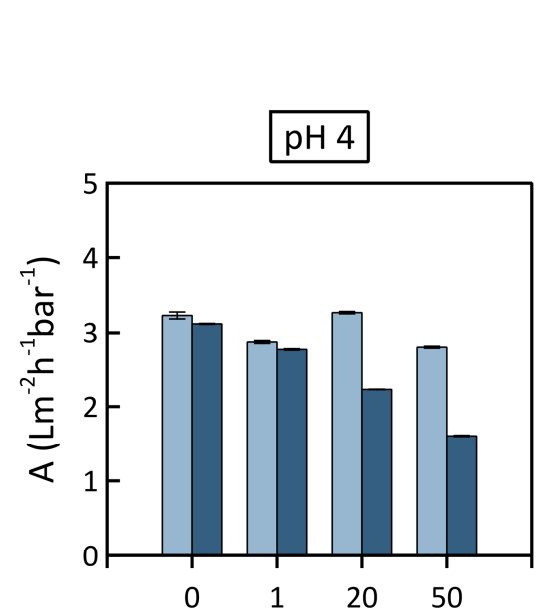

$\mathrm{pH} 7$
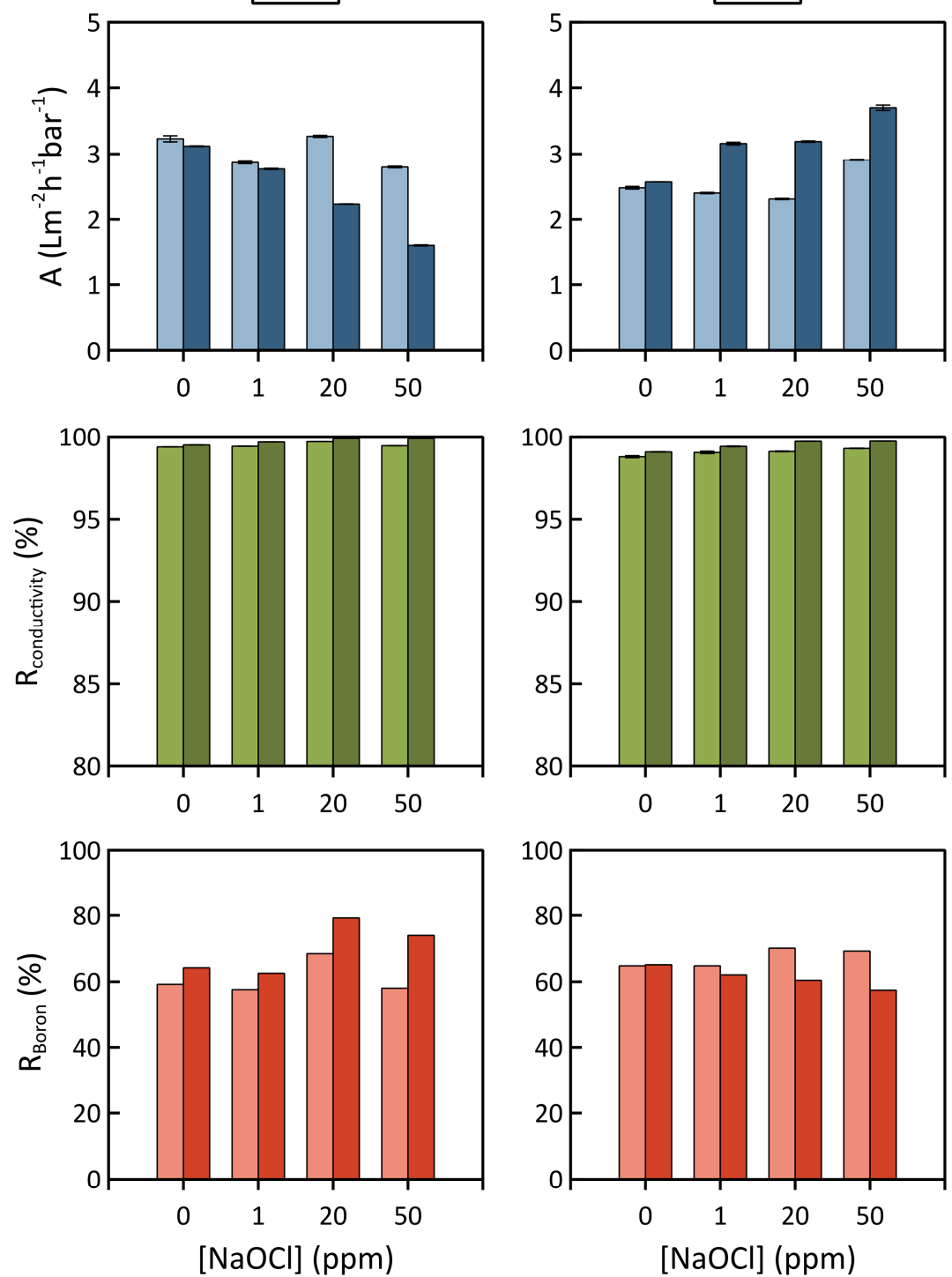
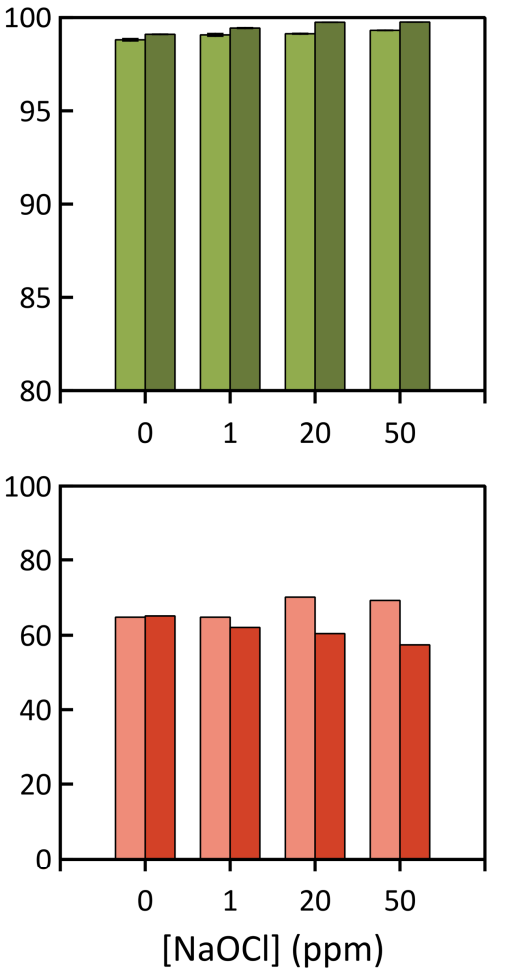

$\mathrm{pH} 10$
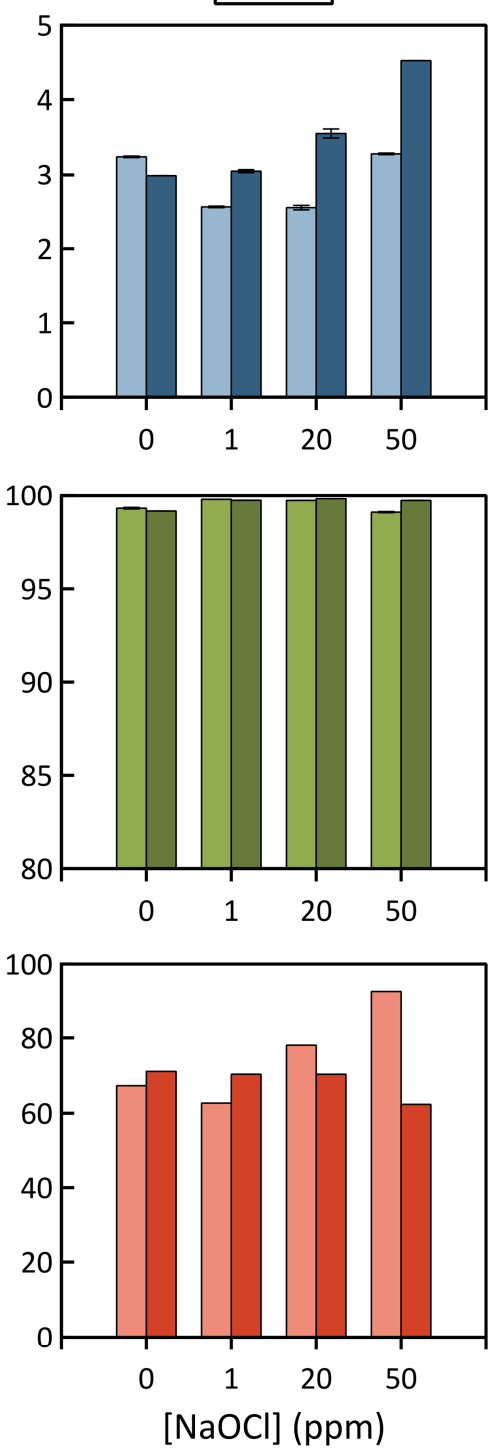

Figure 2. Steady-state water permeability values $(A)$ and observed salt rejection $\left(R_{\text {conductivity }}\right)$ and observed boron rejection $\left(\mathrm{R}_{\text {Boron }}\right)$ of the pre- and post-Cl-ST for each membrane chlorinated at $\mathrm{pH} \mathrm{4,} \mathrm{pH} 7$ and 10 as a function of $\mathrm{NaOCl}$ concentration. Observed salt rejection is determined using conductivity measurements. Experimental conditions of pre- and post-Cl-ST: RO permeate at 15.5 bar with $\mathrm{NaCl}(2000 \mathrm{ppm})$, isopropanol $(100 \mathrm{ppm})$ and boric acid $(5 \mathrm{ppm})$, at $\mathrm{pH} 8$, at $25^{\circ} \mathrm{C}$ and at a recovery of $15 \%$.

After alkaline and neutral chlorination, both water permeability and salt rejection significantly increase over the whole $\mathrm{NaOCl}$ concentration range, although not proportionally with chlorine concentration

(Figure 1b,c). This is likely due to the intermittent and low dosage of chlorine in the feed solution. Nonetheless, the biggest improvement in terms of membrane salt rejection and water permeability occurs after chlorination with $20 \mathrm{ppm} \mathrm{NaOCl}$ at pH 7 and with $50 \mathrm{ppm} \mathrm{NaOCl}$ at pH 10. A tremendous increase of $+40 \%$ in water permeability and ca. $+0.6 \%$ in salt rejection is observed in both cases. More 
and salt rejection from 99.09 to $99.70 \%$. For pH 10 with $50 \mathrm{ppm} \mathrm{NaOCl}$, water permeability increased from 3.28 to $4.53 \mathrm{Lm}^{-2} \mathrm{~h}^{-1}$ bar $^{-1}$ and observed salt rejection from 99.07 to $99.69 \%$ (Figure 2, and Figure S46 for salt passage). As the chlorinated membranes achieve a concurrent improvement of salt rejection and water permeability, the typical permselectivity trade-off $(A / B$ as a function of $A)$ is not followed. Indeed, the upper bound limit is approached or even slightly exceeded after chlorination with $20 \mathrm{ppm}$ and $50 \mathrm{ppm} \mathrm{NaOCl}$ at pH 7 and pH 10, respectively (Figure $3 \mathbf{b}, \mathbf{c}$ ). Thus, when controlled chlorination of membrane modules is executed prior to their use, it can improve the short-term membrane water/salt permselectivity.

On the other hand, the rejection of boron decreased over the whole $\mathrm{NaOCl}$ concentration range after neutral and alkaline chlorination, except for $1 \mathrm{ppm}$-chlorination at pH 10 (Figure 1d). This is most pronounced at $\mathrm{pH} 10$ with $50 \mathrm{ppm} \mathrm{NaOCl}$, where observed boron rejection decreased from $92.65 \%$ to $62.35 \%$, or a drop of $32.7 \%$ from the initial value (Figure 2, and Figure S4-6 for boron passage). However, the rejection of IPA, a neutral but larger solute than boron [41,42], did not change significantly $(<1.5 \%$ difference between pre- and post-Cl-ST) or even slightly increased after alkaline and neutral chlorination (Figure S2). This indicates that controlled chlorination can induce changes to the PA that cause decreased boron rejection but that do not negatively affect the rejection of charged or larger neutral solutes. Neutral ( $\mathrm{pH} \mathrm{7)}$ and alkaline ( $\mathrm{pH} 10)$, low dose $(20-50 \mathrm{ppm})$ and short time $(<2.5 \mathrm{~h})$ chlorination thus appears as a promising modification strategy to achieve short-term high plant productivity with increased salt rejection, at least for feed waters with low boron content, such as most river waters or process water recycle streams.
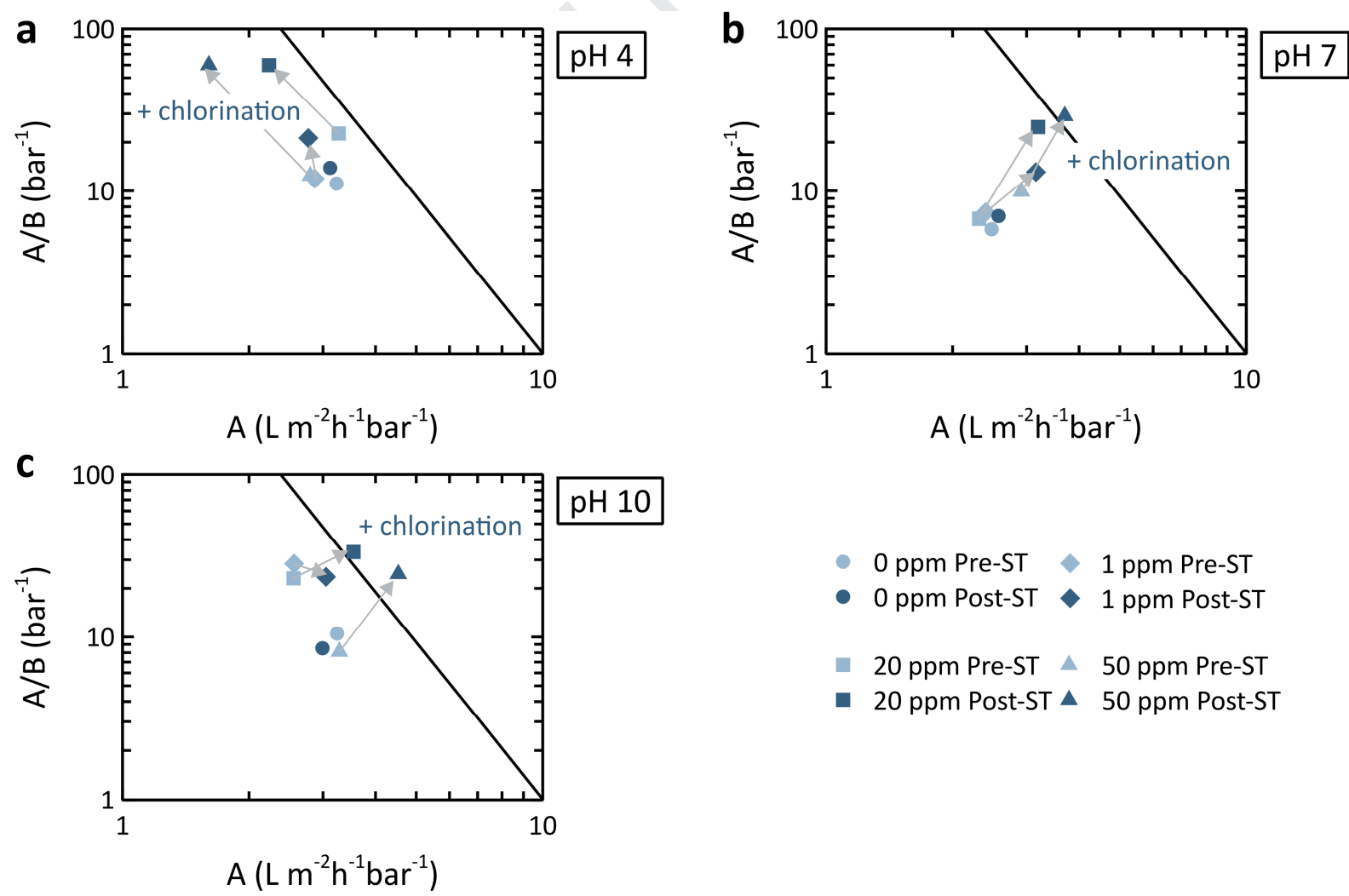

Figure 3. The water/ $\mathrm{NaCl}$ permeability-selectivity trade-off for chlorinated membranes as a function of $\mathrm{NaOCl}$ concentration and $\mathrm{pH}$, with a) $\mathrm{pH} 4, \mathbf{b}) \mathrm{pH} 7$ and c) $\mathrm{pH} 10$. The upper bound function equals $A / B=1600 A^{-3.2}$, according to [34]. Reported 
values are based on steady-state salt rejection and water permeate flow during pre- and post-Cl-ST. Experimental conditions of pre- and post-Cl-ST: RO permeate at 15.5 bar with $\mathrm{NaCl}(2000 \mathrm{ppm})$, isopropanol $(100 \mathrm{ppm})$ and boric acid $(5 \mathrm{ppm})$, at pH 8 , at $25^{\circ} \mathrm{C}$ and at a recovery of $15 \%$.

These results show that controlled chlorination at $\mathrm{pH} 7$ and $\mathrm{pH} 10$ with $\mathrm{NaOCl}$ concentrations even below $50 \mathrm{ppm}$ is able to drastically modify membrane performance, both with respect to increased water permeability as to increased salt rejection. This is in line with few reports in literature, where improved performance after chlorination was observed. This was done by immersing small membrane coupons in the chlorinating solution and subsequent filtration. However, the employed doses varied between 100 and $2000 \mathrm{ppm} \mathrm{NaOCl}$ with contact times between $10 \mathrm{~min}$ and 100 hours [23-29]. One study was executed on membrane modules, but without applying pressure [43]. A non-exhaustive literature overview is given in Table S1. Conversely, in this study at industrial scale conditions, membrane modules are used, compared to small membrane coupons, and the membrane modules are actively permeating under 10 bar when chlorination occurs. That is most probably why the employed $\mathrm{NaOCl}$ concentrations (max. $50 \mathrm{ppm}$ ) and contact times $(2.5 \mathrm{~h})$ can be significantly lower and improve membrane performance even more drastically. The implementation of a short, low-dose $\mathrm{NaOCl}$ treatment at $\mathrm{pH} 7$ and $\mathrm{pH} 10$ on membrane modules in water treatment plants prior to their use in the actual separation process, could thus significantly boost membrane separation capacity and process productivity. Additionally, it could also decrease the energetic cost of the filtration step as lower pressures are required to achieve same permeate fluxes.

For lab-scale studies aiming to better mimic and understand industrial chlorination, experimental design could be improved (i) by applying $\mathrm{NaOCl}$ solely to the top-layer, (ii) by chlorinating in cross-flow mode and under pressure while the membrane is actively permeating, and (iii) by using small spiral wound modules. Additionally, research on whether these one-time chlorination events cause long-term and stable performance changes is highly needed, as neither this study, nor any studies reported in literature, have reported evidence of this. Future studies should thus also focus on the long-term influence of chlorination on membrane performance.

\subsection{Influence of chlorination on membrane physicochemical properties}

The differences in membrane performance due to chlorinating $\mathrm{pH}$ can be related to the different chlorination mechanisms that occur under different $\mathrm{pH}$ regimes [18]. The available chlorine in the form of hypochlorous acid $(\mathrm{HOCl})$ is approximately $100 \%$ at pH $4, \mathrm{ca} .75 \%$ at $\mathrm{pH} 7$ and ca. $0 \%$ at $\mathrm{pH} 10$. At pH 4, $\mathrm{HOCl}$ causes $\mathrm{N}$ - and direct ring-chlorination, or indirect ring-chlorination through Orton rearrangement [44]. Under neutral conditions, ring- and $\mathrm{N}$ - chlorination become comparable in magnitude [45-47]. At pH 10, N-chlorination is followed by hydrolysis [44]. These different reactions alter the membrane physicochemical properties differently. The induced changes of real-scale chlorination on the membrane surface roughness, charge and chemical bonds as well as the extent of chlorine uptake in the PA network were therefore investigated.

ATR-FTIR reveals $\mathrm{N}$-chlorination and changes in $\mathrm{H}$-bonding under all $\mathrm{pH}$ values by, amongst others, a shift to lower wavenumbers and a decrease in intensity of the amide II band $\left(1542 \mathrm{~cm}^{-1}\right)$ (the effects of 20 ppm are shown in Figure 4a, other concentrations are depicted in Figure S7) $[46,48]$. The broad peak around $3300 \mathrm{~cm}^{-1}$ also decreases in intensity, which is indicative for (partial) degradation of the coating layer and $\mathrm{N}$-chlorination $[49,50]$. These changes are most pronounced at $\mathrm{pH} 4$, indicating that acidic chlorination is most severe. Additionally, at pH 4 and pH 7 the intensity of the $1609 \mathrm{~cm}^{-1}$ peak 
decreases, representative for $\mathrm{C}=\mathrm{C}$ ring stretching [51] and $\mathrm{N}-\mathrm{H}$ deformation vibration of the aromatic amide [32]. This suggests the occurrence of ring-chlorination, next to $\mathrm{N}$-chlorination.

XPS was used to quantitatively determine Cl-uptake in the PA network (Table S2-4). However, it should be noted that XPS measures only the upper $10 \mathrm{~nm}$ of the membrane [52], hence the overall XPS spectra contain both the coating layer and the upper side of the PA-layer. Indeed, besides PAcharacteristic signals, peaks from the coating layer (C-O environments) were detected for all samples (Table S4). Discrimination between uptake through ring-chlorination (C-Cl) and N-chlorination (N-Cl) was not possible as only chloride $\left(\mathrm{Cl}^{-}\right)$and $\mathrm{C}-\mathrm{Cl}$ environments, and no $\mathrm{N}-\mathrm{Cl}$ environments, were detected in the high resolution XPS spectra (Table S3). Photo-induced rearrangement of aromatic N-chloroamides to chloroaromatic amides in the solid state has been observed [53]. Degradation of $\mathrm{N}-\mathrm{Cl}$ bonds under exposure to UV-light (e.g. during sample collection) or possibly even under the bombardment with energetic X-rays during XPS measurements can thus have taken place. XPS therefore does not provide evidence for $\mathrm{N}$-chlorination, even though ATR-FTIR suggests its occurrence in all samples (Figure 4a). The measured $\mathrm{Cl}$-uptake (as $\mathrm{Cl}-\mathrm{C}$ ) with $\mathrm{XPS}$ at $\mathrm{pH} 4$ reaches ca. $3 \%$ after $50 \mathrm{ppm} \mathrm{NaOCl,} \mathrm{while} \mathrm{at} \mathrm{pH} 7$, the uptake is 3 times lower for all concentrations. At pH 10, Cl-uptake even falls below 0.5 at\% (Figure 4c). Lower $\mathrm{Cl}$-uptake at $\mathrm{pH} 7$ and $\mathrm{pH} \mathrm{10,} \mathrm{compared} \mathrm{to} \mathrm{pH} 4$, is in agreement with literature [18] and is also reflected in much lower $\mathrm{Cl} / \mathrm{N}$ ratios (as $\mathrm{C}-\mathrm{Cl} /$ amidic $\mathrm{N}$ ) (Figure $4 \mathbf{d}$ ). Surprisingly, XPS evidences $\mathrm{C}$ chlorination under alkaline conditions (ca. 0.5 at\%), as opposed to the currently established chlorination mechanisms. This $\mathrm{Cl}$-uptake might originate from conversion of $\mathrm{N}-\mathrm{Cl}$ to $\mathrm{C}-\mathrm{Cl}$ bonds during XPS measurements or from minimal chlorination of the coating layer, in agreement with [54]. The high intrasample inhomogeneity does not allow to detect significant changes in coating/PA-ratios, even though, especially under acidic chlorination, other characterization techniques do show partial coating degradation [31]. Also, the lower $\mathrm{C}-\mathrm{Cl}$ uptake with increasing $\mathrm{NaOCl}$ concentrations at $\mathrm{pH} 10$ is again most probably due to intra-sample variability related to the low $\mathrm{Cl}$-uptake in the sample. 
a

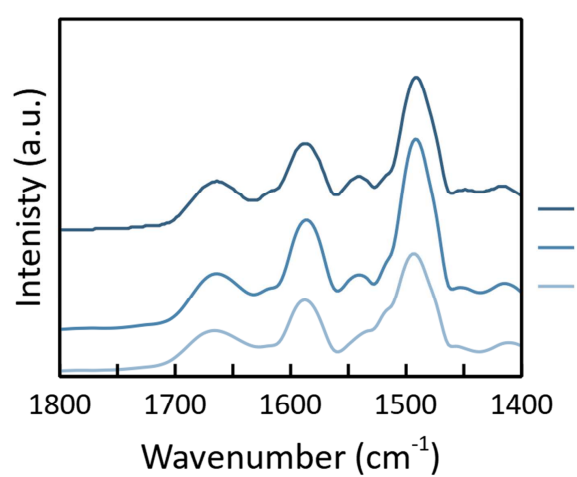

C

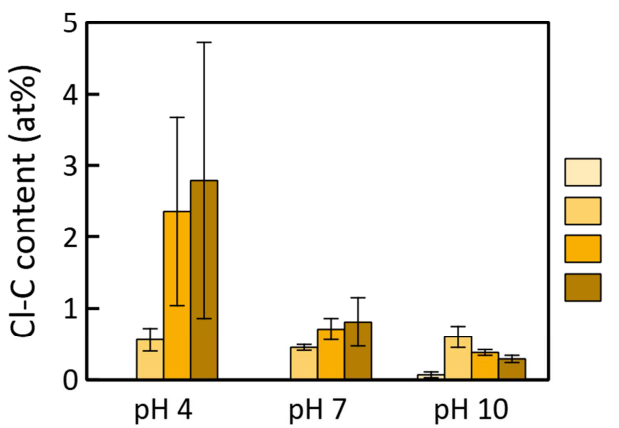

b
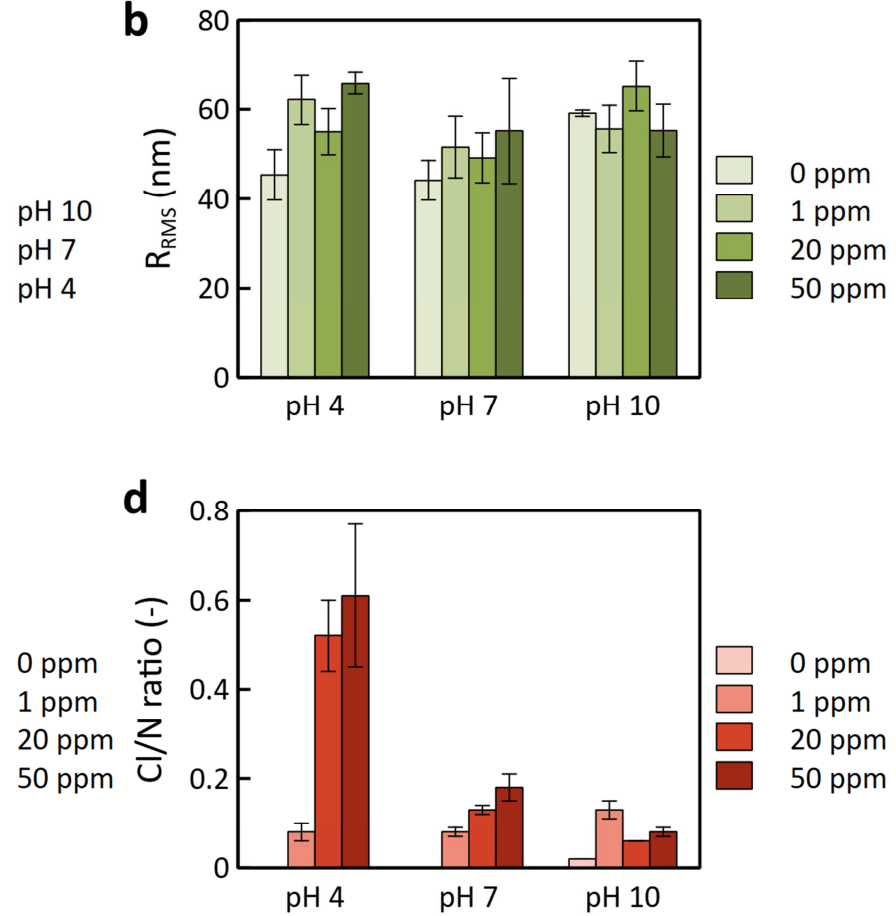

Figure 4. a) Characteristic polyamide FTIR bands of membranes chlorinated with $20 \mathrm{ppm}$ for $2.5 \mathrm{~h}$ at pH 4 , pH 7 and pH 10 . b) Root-mean-square roughness $\left(R_{R M S}\right)$ of the chlorinated membranes as a function of $\mathrm{pH}$ and $\mathrm{NaOCl}$ concentration. Values shown are the average of at least 3 replicates, each of which was obtained by scanning a $5 \times 5 \mu \mathrm{m}^{2}$ surface area. c) Organo-chlorine (C$\mathrm{Cl}$ ) uptake, based on XPS measurements, of the chlorinated membranes as a function of $\mathrm{pH}$ and $\mathrm{NaOCl}$ concentration. d) $\mathrm{Cl} / \mathrm{N}$ ratio of the chlorinated membranes as a function of $\mathrm{pH}$ and $\mathrm{NaOCl}$ concentration, based on XPS measurements of $\mathrm{C}-\mathrm{Cl}$ and amidic-N content.

Furthermore, chlorination-promoted hydrolysis is expected to occur under alkaline conditions, increasing the carboxylic acid content $[18,44]$. However, no significant differences in COOH-content, measured with XPS, between the reference $(0 \mathrm{ppm})$ and the chlorinated membranes exist, suggesting that chlorination-induced hydrolysis is not measurable or prevalent under the applied conditions at $\mathrm{pH}$ 10 (Table S4). The $\zeta$-potential curves of the reference membranes are also surprisingly lower than the chlorinated membranes (Figure S8). This is contrary to literature, where a more negative surface charge and an increased surface charge density is observed after severe chlorination [23,54,55]. Also, no trend between $\mathrm{NaOCl}$ concentration and zeta-potential at each $\mathrm{pH}$ values is observed. The inherent sensitivity of $\zeta$-potential measurements to ion-sorption [56] hampers correct interpretation of the relative positions of the $\zeta$-potential curves, especially when the chlorination conditions are very mild. $\zeta$-potential and XPS measurements therefore do not provide evidence that the increased salt rejection at pH 10 is attributed to an increased surface charge originating from carboxylic acid groups, as could be assumed from charge-exclusion theory. Other novel or more sensitive characterization techniques are thus needed to better understand the subtle but fundamental changes in chemical composition that alter membrane performance after chlorination.

AFM evidences a slight increase in surface roughness $\left(R_{R M S}\right)$ after acidic chlorination, as opposed to $\mathrm{pH} 7$ and $\mathrm{pH} 10$, where no significant difference between the chlorinated and reference membranes is observed (Figure $\mathbf{4 b}$, and Figure $\mathbf{5 9}$ for AFM images). The non-chlorinated membrane at $\mathbf{p H} \mathbf{1 0}$ is also substantially rougher than those at $\mathrm{pH} 4$ and $\mathrm{pH} 7$, suggesting that the $\mathrm{pH}$ of the feed solution affects 
membrane roughness. The integrity of the coating layer could also be affected by pH-treatment, however, XPS shows that these membrane have similar C-O content (Table S4). Additionally, the high variability amongst (pristine) membrane samples makes it perilous to draw decisive conclusions on the influence of chlorination on membrane roughness [44,57]. Similarly, the top-view SEM images for the membranes chlorinated under alkaline and neutral conditions are not distinct (Figure S10). Membranes chlorinated at $\mathrm{pH} 4$ appear to be less smooth than the reference membrane, caused by degradation of the coating layer, as also suggested by ATR-FTIR. This again indicates that chlorination at $\mathrm{pH} 4$ alters the membrane physiochemical properties more severely.

\subsection{Relation between chlorination conditions and membrane performance}

A recent electrochemical impedance spectroscopy (EIS) study revealed that $\mathrm{N}$-chlorination decreases polymer swelling, lowering water and ion permeation [44]. In this study, at acidic $\mathrm{pH}$, the occurrence of $\mathrm{N}$-chlorination was confirmed by ATR-FTIR and water permeability decreased, while salt and boron rejection increased. When correlating the results in this study to those observed with EIS, the changes is membrane performance could result from a decrease in polymer swelling due to $\mathrm{N}$-chlorination at $\mathrm{pH} 4$. This change in polymer confirmation is in agreement with positron annihilation measurements which showed a decrease in the size of the free-volume elements inside the PA layer [31]. Also, it appears that a decrease in polymer swelling and free-volume hole size more strongly affects the rejection of neutral solutes, compared to salts (e.g., for $50 \mathrm{ppm} \mathrm{NaOCl}$ at $\mathrm{pH} 4$ : salt rejection increased with $0.4 \%$, while boron rejection increased with almost 30\%). This could substantiate the charge exclusion theory for charged solutes and size exclusion theory for neutral solutes, assuming that polymer swelling does not influence the accessibility of charged groups.

For alkaline and neutral chlorination, the relation between chlorination conditions and membrane properties and performance is more complicated. EIS shows that chlorination-promoted hydrolysis, occurring under alkaline conditions, increases water and ion permeation by hypochlorite-promoted amide bond hydrolysis [44]. However, in this work, both water permeability and salt rejection increase under alkaline chlorination. In the upper $\sim 10 \mathrm{~nm}$ of the membrane top-layer, no evidence for amide cleavage is found. ATR-FTIR demonstrates that there is some chlorine uptake in the layer, but that it is quantitatively very low, according to XPS. Also with elastic recoil detection (ERD), no obvious evidence of amide cleavage deeper inside the layer is found [58]. Likewise, other investigated membrane physicochemical properties remained relatively unaltered. The cause of the improved membrane performance after chlorination at $\mathrm{pH} 7$ and $\mathrm{pH} 10$ is thus most probably not measurable with the applied characterization techniques. It could originate from alterations in the ultrathin selective parts within the membrane, which only make up a fraction of the complete membrane [59].

It should be noted that chlorination in this work was conducted under pressure, while EIS measurements and most other lab-scale chlorination experiments were not. As previously observed, application of pressure does alter membrane performance and physicochemical properties differently $[31,58]$ and could hence be one of the parameters explaining the observed differences. Additional research is needed to clarify which mechanisms are at the base of the improved membrane separation capacity after pressure-induced chlorination. 


\section{Conclusions}

In order to better understand the effects of accidental chlorination of PA TFC membrane modules in a water treatment plant, controlled chlorination (0-50 ppm NaOCl; $\mathrm{pH} 4-7-10 ; 2.5 \mathrm{~h}$ ) of real-scale 8" BW30 membrane modules was conducted. Rather surprisingly, the results demonstrated that controlled membrane chlorination for short times $(2.5 \mathrm{~h})$ and low $\mathrm{NaOCl}$ concentrations $(<50 \mathrm{ppm})$ prior to their use in separation processes can provide an easy and cheap route to achieve improved membrane performance, increased process productivity or decreased energy use. The changes in membrane performance however were highly dependent on the $\mathrm{pH}$ used, substantiating the importance of controlling the $\mathrm{pH}$ when chlorination would be used on purpose to modify membrane desalination performance. Low dose chlorination at $\mathrm{pH} 4$ namely decreases water flux but increases both salt, boron and IPA rejection. Low dose chlorination at $\mathrm{pH} 7$ and $\mathrm{pH} 10$ increases water flux and salt rejection, approaching or even slightly exceeding the upper bound salt/water selectivity-permeability limit. Negligible influence of alkaline and neutral chlorination on IPA rejection is found, however, boron rejection significantly decreased. Minimal changes in membrane physicochemical properties are observed due to the low chlorination dose and because of the intrinsic limitations of the used traditional characterization techniques (XPS, SEM and zeta-potential measurements). Additionally, comparison with lab-scale studies reveals a discrepancy between the time and $\mathrm{NaOCl}$ dose needed to achieve similar performance changes at lab-scale and at real-scale. These results indicate that chlorination could be a useful pretreatment procedure to boost the performance of membrane modules in certain applications, and should foster future fundamental lab-scale studies to better optimize experimental design to more adequately mimic real-scale practices.

\section{Declaration of competing interest}

There are no conflicts of interests to declare.

\section{CRediT authorship contribution statement}

Rhea Verbeke: design, coordination and performance of experiments, data analysis, manuscript writing and redaction. Samuel Eyley and Wim Thielemans: XPS experiments and data analysis. Anthony Szymczyk: zeta-potential experiments and data analysis. Ivo F.J. Vankelecom: supervision and manuscript reviewing.

\section{Appendix A. Supplementary data}

Schematic overview of the pilot-scale RO plant; observed salt and boron passage, and TOC rejection of the pre- and post-Cl-ST for chlorination at $\mathrm{pH} \mathrm{4,} \mathrm{pH} 7$ and $\mathrm{pH} 10$; literature overview of membranes with improved performance after chlorination; ATR-FTIR spectra, XPS-determined elemental compositions, zeta potential curves, AFM images and top-view SEM images of all chlorinated membranes.

\section{Acknowledgements}

The authors thank Research Foundation Flanders (FWO) for support through the Nanomexico SBOgrant. R.V. thanks FWO for her SB-PhD fellowship (1S00917N). A. Volodin (Solid State Physics from KU Leuven) is acknowledged for the AFM measurements. T. Stassin is kindly acknowledged for recording SEM images and for his valuable input. W.T. and S.E. thank FWO (G.0C60.13N), KU Leuven (OT/14/072) and the European Union's European Fund for Regional Development, Flanders Innovation \& 
Entrepreneurship and the Province of West-Flanders (Accelerate3 project, Interreg VlaanderenNederland programme) for financial support. W.T. also thanks the Province of West-Flanders for his Provincial Chair in Advanced Materials.

\section{References}

[1] E. Jones, M. Qadir, M.T.H. van Vliet, V. Smakhtin, S. mu Kang, The state of desalination and brine production: A global outlook, Sci. Total Environ. 657 (2019) 1343-1356. doi:10.1016/j.scitotenv.2018.12.076.

[2] United Nations, Sustainable Development Goals - United Nations, (n.d.) https://sustainabledevelopment.un.org/sdgs.

[3] J.R. Werber, C.O. Osuji, M. Elimelech, Materials for next-generation desalination and water purification membranes, Nat. Rev. Mater. (2016) 16018. doi:10.1038/natrevmats.2016.18.

[4] H.B. Park, J. Kamcev, L.M. Robeson, M. Elimelech, B.D. Freeman, Maximizing the right stuff: The trade-off between membrane permeability and selectivity, Science. 356 (2017) 1138-1148. doi:10.1126/science.aab0530.

[5] L.N. Breitner, K.J. Howe, D. Minakata, Effect of Functional Chemistry on the Rejection of LowMolecular Weight Neutral Organics through Reverse Osmosis Membranes for Potable Reuse, Environ. Sci. Technol. 53 (2019) 11401-11409. doi:10.1021/acs.est.9b03856.

[6] C. Fonseca Couto, L.C. Lange, M.C. Santos Amaral, A critical review on membrane separation processes applied to remove pharmaceutically active compounds from water and wastewater, J. Water Process Eng. 26 (2018) 156-175. doi:10.1016/j.jwpe.2018.10.010.

[7] C. Boo, Y. Wang, I. Zucker, Y. Choo, C.O. Osuji, M. Elimelech, High Performance Nanofiltration Membrane for Effective Removal of Perfluoroalkyl Substances at High Water Recovery, Environ. Sci. Technol. 52 (2018) 7279-7288. doi:10.1021/acs.est.8b01040.

[8] V.S. Freger, H. Shemer, A.A. Sagiv, R.R. Semiat, Boron Removal Using Membranes, in: Boron Sep. Process., 2015: pp. 199-217. doi:10.1016/B978-0-444-63454-2.00008-3.

[9] World Health Organisation, Chemical Facts Sheet: Boron, (2009) 323-324.

[10] M. Zaman, S.A. Shahid, L. Heng, Guideline for Salinity Assessment, Mitigation and Adaptation Using Nuclear and Related Techniques, 2018. doi:10.1007/978-3-319-96190-3.

[11] Z. Ali, Y. Al Sunbul, F. Pacheco, W. Ogieglo, Y. Wang, G. Genduso, I. Pinnau, Defect-free highly selective polyamide thin- film composite membranes for desalination and boron removal, J. Memb. Sci. 578 (2019) 85-94. doi:10.1016/j.memsci.2019.02.032.

[12] S. Shultz, M. Bass, R. Semiat, V. Freger, Modification of polyamide membranes by hydrophobic molecular plugs for improved boron rejection, J. Memb. Sci. 546 (2018) 165-172. doi:10.1016/j.memsci.2017.10.003.

[13] A. Sagiv, R. Semiat, Analysis of parameters affecting boron permeation through reverse osmosis membranes, J. Memb. Sci. 243 (2004) 79-87. doi:10.1016/j.memsci.2004.05.029.

[14] Z. Ali, Y. Al Sunbul, F. Pacheco, W. Ogieglo, Y. Wang, G. Genduso, I. Pinnau, Defect-free highly selective polyamide thin-film composite membranes for desalination and boron removal, J. Memb. Sci. 578 (2019) 85-94. doi:10.1016/j.memsci.2019.02.032. 
[15] Y. Li, S. Wang, X. Song, Y. Zhou, H. Shen, X. Cao, P. Zhang, C. Gao, High boron removal polyamide reverse osmosis membranes by swelling induced embedding of a sulfonyl molecular plug, J. Memb. Sci. 597 (2020) 117716. doi:10.1016/j.memsci.2019.117716.

[16] O. Nir, M. Herzberg, A. Sweity, L. Birnhack, O. Lahav, A novel approach for SWRO desalination plants operation, comprising single pass boron removal and reuse of $\mathrm{CO} 2$ in the post treatment step, Chem. Eng. J. 187 (2012) 275-282. doi:10.1016/j.cej.2012.01.080.

[17] Y. Du, Y. Liu, S. Zhang, Y. Xu, Optimization of seawater reverse osmosis desalination networks with permeate split design considering boron removal, Ind. Eng. Chem. Res. 55 (2016) 1286012879. doi:10.1021/acs.iecr.6b02225.

[18] R. Verbeke, V. Gómez, I.F.J. Vankelecom, Chlorine-resistance of reverse osmosis (RO) polyamide membranes, Prog. Polym. Sci. 72 (2017) 1-15. doi:10.1016/j.progpolymsci.2017.05.003.

[19] American Water Works Association, Facility Design and Construction, in: Reverse Osmosis Nanofiltration - AWWA Man., 2007: pp. 63-165.

[20] C. Gilbert, Avoiding testing errors: protecting RO membranes from chlorine damage., in: Www.Waterworld.Com/Home/Article/16199150/Avoiding-Testing-Errors-Protecting-RoMembranes-from-Chlorine-Damage, 2009.

[21] A. Wachinski, Membrane Processes for Water Reuse, 2013.

[22] R. García-Pacheco, J. Landaburu-Aguirre, A. Lejarazu-Larrañaga, L. Rodríguez-Sáez, S. Molina, T. Ransome, E. García-Calvo, Free chlorine exposure dose (ppm.h) and its impact on RO membranes ageing and recycling potential, Desalination. 457 (2019) 133-143. doi:10.1016/j.desal.2019.01.030.

[23] V.T. Do, C.Y. Tang, M. Reinhard, J.O. Leckie, Effects of chlorine exposure conditions on physiochemical properties and performance of a polyamide membrane-mechanisms and implications, Environ. Sci. Technol. 46 (2012) 13184-13192. doi:10.1021/es302867f.

[24] G.D. Kang, C.J. Gao, W.D. Chen, X.M. Jie, Y.M. Cao, Q. Yuan, Study on hypochlorite degradation of aromatic polyamide reverse osmosis membrane, J. Memb. Sci. 300 (2007) 165-171. doi:10.1016/j.memsci.2007.05.025.

[25] A. Ettori, E. Gaudichet-Maurin, J.C. Schrotter, P. Aimar, C. Causserand, Permeability and chemical analysis of aromatic polyamide based membranes exposed to sodium hypochlorite, J. Memb. Sci. 375 (2011) 220-230. doi:10.1016/j.memsci.2011.03.044.

[26] S.D. Jons, K.J. Stutts, M.S. Ferritto, W.E. Mickols, Treatment of composite polyamide membranes to improve performance. Patent $\mathrm{Nr}^{\circ} 5876602,1999$. doi:10.1016/S0958-2118(00)80090-7.

[27] X. Zhai, J. Meng, R. Li, L. Ni, Y. Zhang, Hypochlorite treatment on thin film composite RO membrane to improve boron removal performance, Desalination. 274 (2011) 136-143. doi:10.1016/j.desal.2011.02.001.

[28] H.D. Raval, J.J. Trivedi, S. V. Joshi, C. V. Devmurari, Flux enhancement of thin film composite RO membrane by controlled chlorine treatment, Desalination. 250 (2010) 945-949. doi:10.1016/j.desal.2009.05.005.

[29] S. Yu, M. Liu, X. Liu, C. Gao, Performance enhancement in interfacially synthesized thin-film 
composite polyamide-urethane reverse osmosis membrane for seawater desalination, J. Memb. Sci. 342 (2009) 313-320. doi:10.1016/j.memsci.2009.07.003.

[30] J.M. Gohil, A.K. Suresh, Chlorine Attack on Reverse Osmosis Membranes: Mechanisms and Mitigation Strategies, J. Memb. Sci. 541 (2017) 108-126. doi:10.1016/j.memsci.2017.06.092.

[31] R. Verbeke, V. Gomez, T. Koschine, S. Eyley, A. Szymczyk, M. Dickmann, T. Stimpel-Lindner, W. Egger, W. Thielemans, I. Vankelecom, Real-scale chlorination at pH4 of BW30 TFC membranes and their physicochemical characterization, J. Memb. Sci. 551 (2018) 123-135. doi:10.1016/j.memsci.2018.01.019.

[32] C.Y. Tang, Y.N. Kwon, J.O. Leckie, Effect of membrane chemistry and coating layer on physiochemical properties of thin film composite polyamide RO and NF membranes. I. FTIR and XPS characterization of polyamide and coating layer chemistry, Desalination. 242 (2009) 149167. doi:10.1016/j.desal.2008.04.003.

[33] C.Y. Tang, Y.-N. Kwon, J.O. Leckie, Effect of membrane chemistry and coating layer on physiochemical properties of thin film composite polyamide RO and NF membranes II. Membrane physiochemical properties and their dependence on polyamide and coating layers, Desalination. 242 (2009) 168-182. doi:10.1016/j.desal.2008.0.

[34] Z. Yang, H. Guo, C.Y. Tang, The upper bound of thin-film composite (TFC) polyamide membranes for desalination, J. Memb. Sci. 590 (2019) 117297. doi:10.1016/j.memsci.2019.117297.

[35] G.M. Geise, H.B. Park, A.C. Sagle, B.D. Freeman, J.E. McGrath, Water permeability and water/salt selectivity tradeoff in polymers for desalination, J. Memb. Sci. 369 (2011) 130-138. doi:10.1016/j.memsci.2010.11.054.

[36] I. Horcas, R. Fernández, J.M. Gómez-Rodríguez, J. Colchero, J. Gómez-Herrero, A.M. Baro, WSXM: A software for scanning probe microscopy and a tool for nanotechnology, Rev. Sci. Instrum. 78 (2007). doi:10.1063/1.2432410.

[37] E. Idil Mouhoumed, A. Szymczyk, A. Schäfer, L. Paugam, Y.H. La, Physico-chemical characterization of polyamide NF/RO membranes: Insight from streaming current measurements, J. Memb. Sci. 461 (2014) 130-138. doi:10.1016/j.memsci.2014.03.025.

[38] I. Hansson, A new set of acidity constants for carbonic acid and boric acid in sea water, Deep. Res. Oceanogr. Abstr. 20 (1973) 461-478. doi:10.1016/0011-7471(73)90100-9.

[39] Z. Yang, H. Guo, C.Y. Tang, The upper bound of thin-film composite (TFC) polyamide membranes for desalination, J. Memb. Sci. 590 (2019) 117297. doi:10.1016/j.memsci.2019.117297.

[40] S. Wang, Y. Zhou, C. Gao, Novel high boron removal polyamide reverse osmosis membranes, J. Memb. Sci. 554 (2018) 244-252. doi:10.1016/j.memsci.2018.03.014.

[41] X.L. Wang, T. Tsuru, S.I. Nakao, S. Kimura, The electrostatic and steric-hindrance model for the transport of charged solutes through nanofiltration membranes, J. Memb. Sci. 135 (1997) 19-32. doi:10.1016/S0376-7388(97)00125-7.

[42] J.K. Park, K.J. Lee, Diffusion Coefficients for Aqueous Boric Acid, J. Chem. Eng. Data. 39 (1994) 891-894. doi:10.1021/je00016a057.

[43] A. Ettori, E. Gaudichet-Maurin, P. Aimar, C. Causserand, Pilot scale study of chlorination-induced 
transport property changes of a seawater reverse osmosis membrane, Desalination. 311 (2013) 24-30. doi:10.1016/j.desal.2012.11.004.

[44] M. Stolov, V. Freger, Degradation of Polyamide Membranes Exposed to Chlorine: An Impedance Spectroscopy Study, in: Environ. Sci. Technol., American Chemical Society, 2019: pp. 2618-2625. doi:10.1021/acs.est.8b04790.

[45] J. Powell, J. Luh, O. Coronell, Bulk Chlorine Uptake by Polyamide Active Layers of Thin-Film Composite Membranes upon Exposure to Free Chlorine: Kinetics and Mechanisms, Environ. Sci. Technol. 48 (2015) 2741-2749. doi:10.1021/acs.est.5b02110.

[46] A. Antony, R. Fudianto, S. Cox, G. Leslie, Assessing the oxidative degradation of polyamide reverse osmosis membrane-Accelerated ageing with hypochlorite exposure, J. Memb. Sci. 347 (2010) 159-164. doi:10.1016/j.memsci.2009.10.018.

[47] J. Powell, J. Luh, O. Coronell, Amide Link Scission in the Polyamide Active Layers of Thin-Film Composite Membranes upon Exposure to Free Chlorine: Kinetics and Mechanisms, Environ. Sci. Technol. 49 (2015) 12136-12144. doi:10.1021/acs.est.5b02110.

[48] Y.N. Kwon, C.Y. Tang, J.O. Leckie, Change of chemical composition and hydrogen bonding behavior due to chlorination of crosslinked polyamide membranes, J. Appl. Polym. Sci. 108 (2008) 2061-2066. doi:10.1002/app.25657.

[49] C.Y. Tang, Y.N. Kwon, J.O. Leckie, Probing the nano- and micro-scales of reverse osmosis membranes-A comprehensive characterization of physiochemical properties of uncoated and coated membranes by XPS, TEM, ATR-FTIR, and streaming potential measurements, J. Memb. Sci. 287 (2007) 146-156. doi:10.1016/j.memsci.2006.10.038.

[50] N. Dam, P.R. Ogilby, On the mechanism of polyamide degradation in chlorinated water, Helv. Chim. Acta. 84 (2001) 2540-2548.

[51] G. Zheng, H. Lian, J. Xing, L. Shenz, Chlorination and Oxidation of Aromatic Polyamides. 1 . Synthesis and Characterization of Some Aromatic Polyamides, J. Appl. Polym. Sci. 61 (1996) 415420.

[52] C.D. Easton, C. Kinnear, S.L. McArthur, T.R. Gengenbach, Practical guides for $\mathrm{x}$-ray photoelectron spectroscopy: Analysis of polymers, J. Vac. Sci. Technol. A Vacuum, Surfaces Film. 38 (2020). doi:10.1116/1.5140587.

[53] P. Naumov, Y. Topcu, M. Eckert-Maksić, Z. Glasovac, F. Pavošević, M. Kochunnoonny, H. Hara, Photoinduced rearrangement of aromatic $\mathrm{N}$-chloroamides to chloroaromatic amides in the solid state: Inverted $\Pi n-\Sigma N$ occupational stability of amidyl radicals, J. Phys. Chem. A. 115 (2011) 78347848. doi:10.1021/jp203771c.

[54] V.T. Do, C.Y. Tang, M. Reinhard, J.O. Leckie, Degradation of polyamide nanofiltration and reverse osmosis membranes by hypochlorite, Environ. Sci. Technol. 46 (2012) 852-859. doi:10.1021/es203090y.

[55] A. Simon, L.D. Nghiem, P. Le-Clech, S.J. Khan, J.E. Drewes, Effects of membrane degradation on the removal of pharmaceutically active compounds (PhACs) by NF/RO filtration processes, J. Memb. Sci. 340 (2009) 16-25. doi:10.1016/j.memsci.2009.05.005.

[56] R. Zimmermann, U. Freudenberg, R. Schweiß, D. Küttner, C. Werner, Hydroxide and hydronium 
ion adsorption - A survey, Curr. Opin. Colloid Interface Sci. 15 (2010) 196-202. doi:10.1016/j.cocis.2010.01.002.

[57] T.E. Culp, Y. Shen, M. Geitner, M. Paul, A. Roy, M.J. Behr, S. Rosenberg, Electron tomography reveals details of the internal microstructure of desalination membranes, Proc. Natl. Acad. Sci. 115 (2018) 8694-8699. doi:10.1073/pnas.1804708115.

[58] R. Verbeke, A. Bergmaier, S. Eschbaumer, V. Gómez, G. Dollinger, I.F.J. Vankelecom, Elemental depth-profiling of chlorinated polyamide-based TFC-membranes with Elastic Recoil Detection, Environ. Sci. Technol. (2019) acs.est.8b07226. doi:10.1021/acs.est.8b07226.

[59] N. Fridman-Bishop, V. Freger, What Makes Aromatic Polyamide Membranes Superior: New Insights into Ion Transport and Membrane Structure, J. Memb. Sci. 540 (2017) 120-128. doi:10.1016/j.memsci.2017.06.035. 
Highlights:

- Controlled chlorination at pH 4, pH 7, pH 10 with 0-50 ppm NaOCl was executed on commercial, real-scale BW30 membrane modules.

- Controlled membrane chlorination prior to their use in separation processes can provide an easy and cheap route to achieve improved membrane performance, increased process productivity or decreased energy use.

- Low dose $(50 \mathrm{ppm})$ acidic chlorination $(\mathrm{pH} 4)$ decreases water flux $(-40 \%)$ and increases salt $(+0.4 \%)$, boron (+27\%) and isopropanol (8\%) rejection.

- Low dose neutral (20 ppm NaOCl, pH 7) and caustic (50 ppm NaOCl, pH 10) chlorination increases water flux $(+40 \%)$ and salt rejection $(+0.6 \%)$, decreases boron $(-17 \%$ and $-33 \%$, respectively) rejection, and has negligible influence on isopropanol rejection.

- Comparison with lab-scale studies reveals a discrepancy between the time and $\mathrm{NaOCl}$ dose needed to achieve similar performance changes at lab-scale and at real-scale. 